\title{
Partnership and the limits of procedure: prospects for relationships between parents and professionals under the new Public Law Outline
}

\author{
Karen Broadhurst* and Kim Holt $\dagger$ \\ *Lecturer in Applied Social Science, Department of Applied Social Science, Bowland North, Lancaster University, \\ Lancaster, and †Social Worker, Barrister, Senior Lecturer, Programme Director for the BA in Social Work, Bradford \\ University, Bradford, UK
}

Correspondence:

Karen Broadhurst,

Department of Applied Social

Science,

Bowland North,

Lancaster University,

Lancaster, LA1 4YN,

UK

E-mail: k.broadhurst@lancaster.ac.uk

Keywords: care proceedings, parents, partnership, procedures,

relationships

Accepted for Publication: June 2009

Published online: September 2009

\begin{abstract}
April 2008 saw the introduction of a new Public Law Outline (PLO) that aims to improve judicial case management of Public Law Children Act cases. The PLO is a response to concerns about the rising number of care proceedings, associated costs, and the difficulties of achieving case resolution given this volume. Based on an ethos that care proceedings should be avoided wherever possible, the new approach to case management, which places significant emphasis on pre-proceedings work and the effective engagement of parents, can be seen to reinforce the 'no order principle' enshrined in the Children Act (CA) 1989. Focusing specifically on relationships between parents and professionals, this paper provides a critical discussion of the potential of the PLO to further promote consensual practices with parents. Discussion traces the introduction of the concept of partnership within the CA 1989, provides a review of the evidence to-date of effective partnership working, before considering the prospects for the PLO with respect to parental engagement. A number of key contextual obstacles are highlighted that will inevitably undermine the aspirations of the new outline, and a more general observation is drawn about the limits of procedure in effecting change in complex social issues.
\end{abstract}

\section{INTRODUCTION}

The new Public Law Outline (PLO), introduced in April 2008, revises the earlier legislation and protocol for judicial case management of Public Law Children Act cases (Ministry of Justice [MoJ] 2008). Having a number of 'streamlining' intentions, the PLO seeks to reduce delay for children and ensure more effective and economic case management. It is envisaged that, in further reinforcing the 'no order principle' enshrined in the Children Act (CA) 1989, it may also serve to reduce the volume of applications for care orders. Critical to the aspirations of the PLO are effective and co-operative partnerships between parents $^{1}$ and professionals, and it is upon this particular issue that we focus in this paper. Discussion initially traces the introduction of the concept of 'partnership' with the CA 1989 and provides a review of the evidence of effective partnership working to date, before considering in some detail the prospects for the PLO. Our contention is that there is little new in the ethos and commitments of this new set of procedures with respect to reinforcing the 'no order' principle and encouraging consensual solutions with parents and extended family. Indeed, as we will show, these principles have a long history given the ethos of CA 1989 with respect to partnership working. The PLO is largely procedural, and this begs the question of whether further procedural delineation of this complex area of work will serve to ameliorate the 
much-documented difficulties of effecting consensual solutions in the context of child protection.

The PLO is a response to both the Thematic Review published by the Judicial Review Team (Judicial Review Team 2005) and the Review of Child Care Proceedings in England and Wales commissioned by the former Department for Constitutional Affairs (Department for Constitutional Affairs 2006a). These analytic reviews sought to identify the causes of delay/ inefficiencies in child care proceedings and in identifying a number of exacerbating factors, once again drew attention to the importance of parental engagement in ensuring effective decisions for children,

It is also clear that children can suffer because parents and families are insufficiently engaged in the process both preproceedings and during the progress of the case. (Foreword to The PLO, Ministry of Justice 2008)

Under the PLO, and given professionals are tasked to divert cases from care proceedings wherever safe and desirable, the new procedures reinforce the importance of coordinated, multi-agency planning and recommends that essential assessment work is complete before cases are brought before the courts. Pre-proceedings work should include the routine completion of the Core Assessment (Department of Health 2000). Thus, greater demands are made of local authorities with regard to assessment and family support. Documentation detailing discussions with families that provides evidence that voluntary, nonlegal solutions have been sought in the first instance must now be filed with the court. Reflecting the PLO's central concern with improving parental engagement, paragraphs 3.24 and 3.32 of the revised Children Act guidance (Volume 1, Court Orders, Department for Children, Schools and Families 2008) cite the utility of the family group conference (FGC) in facilitating the engagement of friends and wider family at an early stage, with respect to substitute care. When cases are brought before the courts, increased responsibility is placed on professionals to ensure that parents understand court processes, and that intentions to initiate proceedings are explained to the child and parent using appropriate language and methods of communication. Assessment must take into account parents' capacities to instruct a legal representative. Effective parental engagement is also seen as providing the possibility of narrowing the issues brought before the courts, thus leading to swifter case resolution.

Under the revised Children Act guidance (Department for Children, Schools and Families 2008), a range of professionals are implicated in partnership work with parents; however, the case-holding, localauthority social worker will continue to be a key player in promoting parental engagement. As is discussed in the following sections, whilst the concept of partnership working has a long history, the difficulties of establishing partnerships with parents appear to endure. Thus, it is important to consider the prospects of the PLO with respect to both this history and current contextual issues.

\section{PARTNERSHIP - A BRIEF HISTORY}

During the late 1980s a number of important studies, inquiry reports and government commissioned reviews (Department of Health and Social Security 1985a; De'Ath \& Pugh 1985-1986; Pugh et al. 1987; Butler-Sloss 1988; Aldgate 1989) paved the way for what we now consider to be a central and guiding principle for effective social work practice with children and families - that is 'partnership working'. Citing the benefits of effective parental engagement for the welfare of children, studies drew attention to the human-rights issues with respect to state intervention within the family (Pugh \& De'Ath 1985; Milham et al. 1986). In particular, increasing calls for a greater degree of power sharing between professionals and parents were soon to be consolidated in policy and legislation through the advent of the Children Act 1989 (CA, 1989) and associated volumes of regulations and guidance. Whilst the word partnership did not appear in the Act, the $1989 \mathrm{DoH}$ guidance document (Department of Health 1989): The Care of Children - Principles and Practice, published prior to the Act's implementation, made very clear its underpinning ethos and aspirations:

The very fundamental changes in thinking and in policy practice and terminology which the implementation of the Act will demand, make this seem a particularly important time to publish a set of basic principles ... partnership, participation, choice, openness, parental responsibility and every child's need for both security and family links are some of the major themes which are common to the principles and to the legislation.

(Cited in Buchanan 1994, p. 5).

With respect to working with parents, the partnership aspirations were evident in this document, with the guidance stating that the local authority should avoid taking actions that would alienate or undermine parents.

Prior to the advent of the CA 1989, the central government commissioned Review of Child Care Law 
(Department for Health and Social Security [DHSS] 1985b) articulated a growing unease about the way in which parents were dealt with under the law at that time, and argued that parents should be allowed to fulfil their 'natural' and 'legal' responsibilities (Department for Health and Social Security 1985b, para. 2.8). Drawing a conclusion that children were best cared for by their families, the review stated that wherever possible, the state should seek to support rather than usurp the responsibilities of parents. Of course, what is commonly described as the 'Cleveland Crisis', further strengthened a growing impetus towards achieving an effective balance between the powers of the state and the rights and responsibilities of parents (Butler-Sloss 1988). Although there has been significant debate about the political context and connotations of the concept of parental responsibility within the CA 1989 (cf. Edwards \& Halpern 1992), there is consensus that the increased range of powers and duties that this Act introduced signified a genuine attempt to ensure parents were supported in the upbringing of their children (Buchanan 1994; Kaganas et al. 1995; Corby et al. 1996). Thus, we see the aspirations of the PLO regarding partnership have a significant history.

Within the detail of the CA 1989, it is possible to identify the range of statute designed to support parental responsibility and partnership practices. In Part 1, s.3(1) of the Act, the concept of parental responsibility is formally laid out - described by Kaganas (1995, p. 8) as the 'lynchpin of partnership ideology'. Throughout the Act, statute supports parental responsibility even when children are subject to intervention from the state. Indeed, under Parts IV and $\mathrm{V}$ of the Act, parents retain parental responsibility when children are subject to care and supervision orders, with the local authority obligated to support contact between parents and children living away from home. The Act's aspiration to support the upbringing of children by their parents (wherever possible) is particularly clear in the no order/least restrictive order (s.1(5)) principle - which as discussed, is now reinforced through the PLO.

In Part III of the Act, a range of statute relating to family support specifically aims to promote voluntary agreements between parents and the state, even when the state provides substitute care (s.20). The advent of the CA 1989, saw the abolition of both the notice that parents were previously required to provide before removing a child from voluntary accommodation (s.13(2) Child Care Act 1980), and the parental rights resolution procedure (s.3, Child Care Act 1980) - two particular aspects of the Child Care Act 1980 that were considered to mediate against effective parental engagement. The partnership principle is also reflected in sections 22, 61 and 64 (CA 1989), that impose a duty on responsible authorities to consult parents, the child concerned and relevant others, before making decisions affecting a child looked after by the local authority. Despite this seemingly robust legislative framework (that clearly aims to support the upbringing of children within their families) the years following the implementation of the Act have seen a significant increase in care proceedings, prompting commentators such as Beckett (2001) to describe a care proceedings 'explosion'. As we discuss in next section, enacting the partnership concept has proved difficult, professionals have faced a range of problems and dilemmas when attempting to establish effective partnerships with parents.

\section{PARTNERSHIP IN PRACTICE: THE RESEARCH EVIDENCE}

from a reading of all the legislation and guidance, a hazy picture of what is envisaged by partnership begins to emerge. It is a collage of rights, duties and recommendations, only some of which are grounded in practice. A great deal of use is made of terms such as 'co-operation' and 'consultation', terms that are vague and that leave considerable room for interpretation and that can mean different things in different situations. (Kaganas 1995, p. 4)

Despite the positive legislation of the CA 1989, a raft of studies has identified the problems of translating the ideals of partnership into practice realities (Buchanan 1994; Department of Health 1995; Thoburn et al. 1995; Woodhouse 1995; Corby et al. 1996; Freeman \& Hunt 1998; Hunt 1998; Harlow \& Shardlow 2006; Holland \& Scourfield 2004; Brophy 2006). Indeed, since the implementation of the CA 1989, and contrary to the intents and ethos of the Act, a very significant rise in applications made to the courts under s.31 (CA 1989) has been evident (Beckett 2001). Study after study has found that the pursuit of consensual solutions in the context of child protection can prove particularly elusive (Nelken 1987; Aldgate 1991; Buchanan 1994; Kaganas et al. 1995; Corby et al. 1996; Hunt et al. 1999; Harlow \& Shardlow 2006; Masson et al., 2008).

In the last extract, Kaganas hints at some of the troubles of the partnership concept, professional discretion will always impact on the enactment of this 'hazy' concept and context matters. Working in partnership with parents where children are considered to be 'in need' is clearly different from working in 
partnership with parents where children are 'at risk of significant harm'. In this latter context, it may only be possible to operate a more restricted form of partnership. A more critical analysis of the CA 1989 with respect to partnership and child protection finds that although social workers must ascertain the wishes and feelings of children and parents, and give due consideration to them in making any decision (CA 1989, s.22(4)(b) and (5)(b)), when cases are brought before the courts there are distinct limits to parental responsibility. The parents of a child in care under s.31 may not remove the child and the exercise of parental responsibility can be significantly restricted when this is required for the child's welfare-CA 1989, s.33(3)(b) and (4). Whilst principles of partnership should apply in both family support and child protection cases, there is differentiation within the law and associated guidance and regulations between these two different sets of circumstances. As Masson (1995) noted, this was reflected in the separate guidance originally issued with the Children Act 1989. The definition of partnership in Volume 2 of the CA 1989 Guidance and Regulations (Department of Health 1991) distinguished 'working in partnership' from 'working under court orders', which Masson (1995, p. 26) argues can serve to 'exclude the parents of children in care from partnership with their social worker'.

There is a somewhat intractable tension within the law and policy between normative concerns with parental autonomy and a children's rights (or more recently, a children's outcomes) perspective (Luckock 2008). Nowhere are these tensions more apparent, than in the context of child protection, where the state, as discussed, can impose clear limitations on parental autonomy (Corby et al. 1996; Brophy 2006). Working with parents in this context can make even a limited form of partnership hard to achieve - note that in care proceedings, the failure of parents to cooperate, is frequently cited as a key precipitating factor (Brophy 2006).

A number of studies have highlighted the difficulties in meaningfully engaging parents at case conference (Burns 1991; Corby et al. 1996; Bell 1999). Participation of fathers has been a key concern with attendance remaining consistently low. In 1999, Bell noted that only $24 \%$ of fathers attended case conferences. Studies have reported that attendance of mothers is higher, but as Bell (1999); Longstaff (1998) noted, attendance cannot easily be equated with participation. Farmer \& Owen (1995) noted only minimal participation from parents, consistent with an earlier study from Thoburn et al. (1995), who reported that in only a very small proportion of case conferences could parents be described as contributing to discussion of risks $(8 \%)$ and registration $(2 \%)$. In relation to core groups, similar issues pertain. Moreover, recent work has substantiated these findings (Bell 2002; Petrie \& Corby 2002; Gallagher \& Jasper 2003). Featherstone (2009) makes the astute observation that the persistence of gender bias in child protection work endures, with fathers remaining only minimally or infrequently involved with child welfare agencies. This is in spite of attempts to 'modernise' the law with respect to fatherhood (Featherstone 2009).

During the 1990s, enthusiasm developed for the FGC model, originating in New Zealand (Marsh \& Crow 1998). However, analysis of the implementation and use of this model has found widespread inconsistencies between local authorities. In addition, skilled work is required to ensure an effective balance between the opinion of professionals and those of family and friends (Marsh \& Crow 1998). Currently there is much support for the FGC model, but given inconsistent developments in the UK, more work needs to be done to establish their effectiveness (Brown 2003). Studies of effective partnership working have claimed that where partnership succeeds, this may have less to do with formal participation at core group or conference and more to do with empathic, open and honest relationships that individual workers strike up with parents/carers (Farmer \& Owen 1995). Of considerable importance to the arguments that we develop later in this paper, is the finding that where adversarial relationships exist between local authority workers and service users, this does necessarily preclude parents carving out positive relationships with their legal representatives and/or advocates Brophy (2006).

Given the focus of this article, the issue of parental involvement in the context of Public Law Children Act cases requires consideration. Evidence on this subject is weak, as noted by Brophy in her recent review of the relevant literature (Department for Constitutional Affairs 2006a). The PLO is specifically concerned to ensure that parents are effectively engaged at the pre-proceedings stage, yet studies report that partnerships in this context are particularly difficult; the initiation of proceedings often results in complete breakdown of relationships between the local authority and parents (Woodhouse 1995; Holland \& Scourfield 2004). The level of conflict between parents and the state stems from discordance between parents' view of the causes for concern and those of the state, as well as disagreement about the need for 
compulsory removal of children (Freeman \& Hunt 1998; Brophy 2006). Freeman \& Hunt (1998) found that there was little agreement between parents and professionals about the grounds for concern and parents were extremely negative about the help offered from the local authority.

Studies have found that parents struggle to make sense of the court process; whilst attempts may be made to offer explanation to parents, processes can confuse and alienate. Appearing in court can be stressful for all parties, but as Freeman \& Hunt's (1998) study highlighted, parents can experience stress even outside of the courtroom. For parents, simply waiting to enter court can be difficult on account of the lack of privacy coupled with a sense of anxiety and shame (Lindley 1994). Research has also found that parents can perceive their statements as inconsequential when weighted against those of professionals (Brophy 2006). Of course, the conversion rates of local authority applications to the granting of orders by the courts appear to bear this out (cf. Welbourne 2008 for a fuller discussion). Parents are only too aware of the contradictions within law and practice, and that their rights as parents can be significantly curtailed where allegations of significant harm are made (Farmer \& Owen 1995).

The recent Care Profiling Study (Masson et al. 2008) indicates some of the ground that the PLO will have to bridge with respect to increasing consensual relationships. The study aimed to provide baseline data on Children Act Public Law cases, given that the DCA commissioned review had identified a dearth of this data (Department for Constitutional Affairs 2006a). From a retrospective analysis of 386 case files in which care proceedings were initiated in 2004, the researchers observed that significant levels of parental non-cooperation were recorded in $72 \%$ of cases. Drawing on case work derived from fifteen local authorities, the researchers reported that children's services had been unable to complete core assessments at the point of application for care orders in a large proportion of cases ( $43 \%$ of the sample) a high number of children were removed in unplanned crisis situations ( $42 \%$ of the sample). Of course when children are removed under Police Protection Orders (PPO, CA 1989, s.46) or Emergency Protection Orders (EPO, CA 1989, s.48), the possibilities for partnership are significantly limited, as neither legal order requires consent from or necessarily consultation with parents. EPOs can be granted ex parte, and PPOs do not require notice or that the case is brought before a court. Moreover, the study drew attention to the limited preventative work that had been possible in the cases prior to the initiation of care proceedings. Thus, the researchers concluded that:

The expectations of local authority practice in preparation for care proceedings under the PLO far exceed what was undertaken or could have been undertaken before action to protect the child in most of the sample cases. (Masson et al. 2008, p. 2)

Thus, evidence, to date, does not hold out much promise for the PLO. Indeed, as we discuss in the next section, in relation to partnership with parents, proponents of the PLO face not only long-standing difficulties, but also a range of more recent contextual barriers.

\section{PARENTAL ENGAGEMENT AND THE PLO: CONTEXTUAL BARRIERS}

Following the introduction of the PLO in April 2008, an initial sharp decline in the number of applications for care proceedings was recorded - this prompted ministerial comment that the PLO had been successful in effectively reducing the need for litigation in childcare matters. However, this trend was fairly short-lived, with a very sharp rise in care proceedings reported towards the end of the same year (Gillen 2009). This sharp increase has been largely attributed to the 'Baby Peter Effect' (Gillen 2009), and there is no doubt that the death of baby Peter, in the context of child welfare's culture of 'error and blame' (White et al. 2009) so clearly played out in The Sun newspaper's sustained attack on key players in Haringey, will have served to resolve many cases of children on the edge of care. However, there are further contextual factors, that are less well documented and that pertain to the issue of parental engagement.

The PLO seeks to reinforce the 'no order principle', through more effective engagement of parents and the extended family; however, the relationship-based work that might facilitate such engagement will be difficult to realize given the current organization of front-line practice. Recent research has documented the erosion of the time available for face-to-face work with families because of the implementation of the Integrated Children's System (ICS) (Broadhurst et al. 2009; Shaw et al. 2009; White \& Broadhurst 2009). The increased administrative demands of the PLO will further burden front-line workers in children's services and as Masson et al. 2008 have commented, this may lead to the perverse outcome that co-operative parents who need help with the upbringing of the 
children find it hard to get a service as local authorities devote more of their resources to administering Children Act Public Law cases.

Given the dominant role of law within the UK with respect to child protection, local authorities will have to find some way of managing the new administrative demands of the PLO, but this will not necessarily result in improved or more effective relationships with parents. For example, under the PLO, it is entirely possible that significantly more use will be made of s.20 (CA, 1989) agreements ${ }^{2}$. This will be a positive move where this constitutes a safe and consensual approach to supporting families. However, in cases where the threshold criteria are met for an order under s.31 (CA, 1989) and s. 20 is used to simply 'buy' the local authority more time (whilst the local authority completes the assessment work required to lodge an application to the courts under s.31), then a number of problems are possible. This use of $\mathrm{s} .20$ will simply shift the locus of 'delay', to a point preproceedings (cf. McKeigue \& Beckett 2008). In addition, safeguards for both children and parents in this context may be weakened - for parents, the importance of access to independent legal representation may not be so evident. Foster placements under s.20 are not scrutinized by the courts, nor are plans for children. In the context of cases that are likely to progress to an application to the court under s.31, then the problems for partnership working are clearparents may feel that they have not been given adequate support to understand or challenge the local authority's plans at an early point.

Similar arguments apply to the planned increase in use of FGCs under the PLO. Shifting decision-making away from courts and into the mediated space of family and friends networks can be seen in many respects as very positive for all stakeholders, however, this shift is based on rather limited evidence of the effectiveness of the FGC model (Brown 2003). As discussed, decision-making in such informal spaces is not subject to independent or external legal scrutiny an independent chair is advised but not always appointed (Barnardo's 2002). The role of the court in child protection cases serves not only to ensure justice for children and parents, but also to hold the local authority accountable for its actions. This latter point is important, because, as Cathy Ashley (Chief Executive of the Family Rights Group) has cautioned (Ashley 2008), there is the distinct possibility that the necessary development of the FGC model will get 'lost in the shortcuts' as resources are increasingly focused on achieving the administrative demands of public law cases (Social Care Experts Blog, 29. October, 2008). There is some debate about the ideological underpinnings of current government enthusiasm for the FGC - this may have less to do with empowering parents and the extended family network, and more to do with 'policy-makers seeking to reduce the bill for looked after children' (Welbourne 2008, p. 5).

In critically appraising the aspirations of the PLO with respect to parental engagement, it is also important to consider shifting concepts of parental responsibility under New Labour. Commentators have argued that under successive New Labour governments, we have witnessed the increasing regulation of parenthood in the name of 'social investment' (Piper 2008). Parents are increasingly placed central in determining life chances for children - particularly with respect to social mobility, but this has resulted in a tougher line on parents and further conditionality attached to parents' rights (Gillies 2005; Piper 2008; Broadhurst 2009). Early in office, the passing of the Crime and Disorder Act 1998 introduced the parenting order - an enduring component of New Labour's coercive welfare strategy. New contractual forms of governance underpinned by legislation in the context of education, social welfare and criminal justice have elevated issues of parental responsibility or obligation, whilst eroding parental rights (Muncie 2006). In the arena of child protection, this shift is manifest through structured, time-limited and targeted plans for parents that have ushered in a less tolerant approach to welfare, for even the most vulnerable of parents (cf. Forrester et al. 2008) for a recent analysis of practitioner attitudes to parents). The introduction of 'twintracking' ${ }^{3}$ has been much discussed with respect to the impact on parents rights (Parkinson 2003; Luckock 2008) - in giving further priority to permanency planning for children, it has been described as significantly at odds with the family support ethos of the Children Act 1989. Whilst families facing enduring deprivations do not easily fit the new regime, an impatient and time-limited ethos is reinforced through statistics for re-referrals and numbers of children subject to repeat child protection plans reinforced through sanctions for local authorities, where statistics fall outside Ofsted parameters. Of course, skilled workers will try to work around this new 'structured' approach to welfare, but partnerships are not easy to achieve where the balance of power between parents and professionals appears to have shifted further in favour of the latter.

Commentators have also argued that the Every Child Matters (ECM) agenda (Department for Education and Skills 2004) has served to further marginalize the 
needs of parents (Grover 2008; Luckock 2008; Broadhurst 2009), given the 'child-centric' focus of the priority outcomes (Hall et al. in press). ECM, reflecting New Labour's preoccupation with investing in children, has reconfigured practice around the 'atomised' child (Hall et al. in press). In ICS, we see that individual child records have now well and truly confined the family file to a place in history.

Under ECM, a strange polarity appears to have emerged - children's interests can be placed in contradistinction to those of their parents. As Luckock (2008, p. 3) writes:

Traditional normative concerns to support family status and parental autonomy are unsettled by contemporary anxieties about child outcomes and social mobility.

Of course, where 'permanency' issues are at stake, this contradistinction will be more pronounced. Every Parent Matters (Department for Education and Skills 2007) to New Labour, but primarily with respect to the potential role parents can play in promoting better outcomes for children. If the formats of new standardized assessment tools (e.g. The Common Assessment Framework), make it difficult for practitioners to even describe the needs of parents, this does not bode well for partnership working.

Finally, we turn to what is perhaps one of the most pressing issues in relation to effective partnership working. As discussed, research suggests that parents can strike up positive relationships with their legal representatives even when relationships have broken down with the local authority (Brophy 2006). This provides parents with an important source of support and can facilitate important dialogue between parents and the local authority with respect to plans for children. However, the PLO, launched at the same time as very significant reforms to the funding of care proceedings and the legal aid budget were introduced, will likely see parents' access to legal representation limited rather than facilitated. Following the Carter Review of Legal Aid and moves towards a 'market-based' reform of its funding, a fixed and graduated scheme for funding legal representation was introduced (Department for Constitutional Affairs 2006b). The new fee structure that replaces the previous arrangement of hourly rate payments (except for advocacy), has been seen as constituting a significant pay cut for legal representatives, resulting in very strong criticism, given that its likely impact does not appear to have been carefully considered (Welbourne 2008).

Attempting to reduce legal costs in family work has raised serious questions about fair access to justice, as
Masson (2008, p. 4) notes: 'Both the level of fees and the negative response to the reform process are likely to result in a reduction in the numbers of experienced solicitors doing this work'. Masson (2008) has suggested that a two-tier system may result in the local authority having a distinct advantage in terms of access to the most experienced legal advice and representation, and in parents, in contrast, struggling to find a representative. Thus, we see yet another example under New Labour of a further shift in the power balance between parents and professionals unequal access to legal representation would be irrefutable evidence of an inequitable balance of power between parents and professionals that would significantly impact on effective partnership working.

A recent study by the King's Institute for the Study of Social Policy, commissioned by the Family Law Bar Association (FLBA), looked at 1600 barristers engaged in 5000 cases. At the time of the study the FLBA was confronted with the first round of cuts; $£ 13 \mathrm{~m}$ over 2 years (over $13 \%$ across the board). In December 2008, the Legal Services Commission (LSC) introduced proposals for further cuts, which would mean cuts of $20 \%$ to $30 \%$ across the board. The King's Institute study found that over $80 \%$ of family law barristers were intending to change their practices, even before the proposals for the second round of yet harsher cuts. Inevitably those regarding legally aided cases as no longer economic are predominantly senior practitioners, whom the system cannot afford to lose. In the face of the $13 \%$ cuts, $40 \%$ of the barristers over 16 years' call indicated their intention to stop or reduce significantly the number of public law final hearings they undertook (Price \& Laybourne 2008).

The importance to families of the work undertaken by the family bar cannot be underestimated; the bar is engaged in the most complex cases, where the importance of good legal representation is essential to ensure justice for children and their families. The consequences where advocacy fails hardly require description: a local authority acting unlawfully, reduced opportunities to challenge professional evidence and children who may be removed from, or returned to, a placement that has not been properly scrutinized by the legal process.

\section{CONCLUSION}

To produce laws designed to regulate politically embarrassing or disruptive social events is to draw further attention to these events as 'social problems' and to raise the expectation that solutions will be found ... neither the events themselves nor 
the factors which caused them to be defined as problems in the first place are likely to be changed to any degree by their re-ordering within the legal system. (King 1995, p. 147)

In this extract, King identifies the limits of law and procedure with respect to complex social problems. In this opening extract, his observations relate to the CA 1989 , but they are all the more prescient given subsequent evaluation of this legislation as discussed. With respect to the PLO, the tensions and complexities of working with parents who are vulnerable or have maltreated their children will not necessarily be reduced through being located within a new set of procedures. For example, difficulties posed by parents' inconsistent progress against drug rehabilitation plans or unexpected impacts of third party influences (e.g. legal representatives, extended family), will largely remain impervious to procedure.

Under the new arrangements specified by the PLO, at each court appearance the court will ask parties and legal representatives what steps have been taken to achieve co-operation, and where parental co-operation has not been achieved, an explanation will be required. However, these new procedural demands may have little direct bearing on the complex and contested relationships between the local authority work and parents on the front line. Procedural developments are based on what King has termed a false premise - that somehow they can be instrumental in effecting change in encounters between parents and professionals that are situated and highly specific. King has argued that 'to present legal decision-making as no more than a stage in the continuing process of protecting the child is to misunderstand the autopoietic nature of law' (King 1995, p. 152).

Arguably, the PLO offers new procedural safeguards to parents and professionals. However, and given competing policy and resource imperatives as discussed, the implementation of the PLO may not yield the outcomes that are intended. Given the increased administrative and bureaucratic demands the PLO is creating, the new procedures may create more problems than it solves. If the PLO serves only to shift 'delay' to pre-proceedings, this will do little to help children and their parents (McKeigue \& Beckett 2008). A whole range of unintended but possibly risky permutations of socio-legal practices may emerge as local authorities and their practitioners strive to manage competing demands. The tenets of instrumental rationalism, which underpin procedural 'innovation', must surely be called into question, given successive legislative failures to ensure effective partnerships with parents in the context of child protection.

Of course, the problem is that when any new administrative process is introduced, questions and energies are then directed at examining whether new processes are working. This is a somewhat inevitable consequence of the self-referential nature of legislation and policy making, but it leaves other perhaps more fruitful lines of enquiry outside of the frame. The following words from Gillen (2009) writing on 'delay' are useful:

Of course delay should be avoided but the PLO does not help with that. The causes of this are to do with a lack of social workers, shortage of experts and so on. You cannot wish those away by using an administrative process. It does not address the realities and it is dispiriting for everyone working in the system to complete mountains of documents. (http:// www.communitycare.co.uk/Articles/2009/01/14/110406/howthe-public-law-outline-is-affecting-care-cases-in-the-wake-ofbaby.html, accessed, 20. April, 2009)

Social work practitioners, who are tasked to carve out effective relationships with some often the most vulnerable parents and carers, have seen more and more of their time for essential relationship-based work eroded. Moreover, they operate in an increasingly regulated and restricted climate, characterized by the standardization of both assessment and response (timescales, formats, off-the-shelf parenting classes and so forth), this is coupled with the diverting of scant resources to criminal justice and a more punitive climate for welfare (Grover 2008). Forecast public-sector cuts will certainly add to these problems. More procedure, which is evidently New Labour's penchant - now in the form of the PLO, may have little impact on the ongoing difficulties of establishing partnerships with parents in this context.

\section{REFERENCES}

Aldgate, J. (1989) Using Written Agreements with Children and Families. Family Rights Group, London.

Aldgate, J. (1991) Partnership with parents: fantasy or reality? Adoption \& Fostering, 15, 5-10.

Ashley, C. (2008) Lost in the short cuts. Social Care Experts Blog, Oct.29.2008. Available at: http://www.communitycare. co.uk/blogs/social-care-experts-blog/2008/10/lost-in-the-shortcuts.html (accessed 10 May 2009).

Barnardo's/ Family Rights Group/ NCH (2002) Family Group Conferences: Principles and Practice Guidance. Barnardo's, Barkingside.

Beckett, C. (2001) The great care proceedings explosion. British fournal of Social Work, 31, 493-501.

Bell, M. (1999) Child Protection: Families and the Conference Process. Ashgate, Andover. 
Bell, M. (2002) Case conferences in child protection. In: The Child Protection Handbook (eds K. Wilson \& A. James), pp. 288-304. Balliere Tindall (Harcourt), London.

Broadhurst, K. (2009) Safeguarding children through parenting support: how does every parent matter? In: Critical Perspectives on Safeguarding Children (eds K. Broadhurst, C. Grover \& J. Jamieson). Wiley-Blackwell, Oxford, in press.

Broadhurst, K., Wastell, D., White, S., Hall, C., Peckover, S., Thompson, K. et al. (2009) Performing initial assessment: identifying the latent conditions for error in local authority children's services. British fournal of Social Work (accessed 19 January 2009), doi:10.1093/bjsw/bcn 162 .

Brophy, J. (2006) Care proceedings under the Children Act 1989: a research review. Research Series /06, Department for Constitutional Affairs, London.

Brown, L. (2003) Family group conferences in child welfare practice in the UK. Child and Family Social Work, 8, 331-340.

Buchanan, A. (1994) Partnership in Practice: The Children Act 1989. Ashgate, Avebury.

Burns, L. (1991) Partnership with Families: A Study of 65 Child Protection Conferences in Gloucestershire to Which the Family Were Invited. Gloucester Social Services Department, Gloucester.

Butler-Sloss, E.J. (1988) Report of the Inquiry into Child Abuse in Cleveland 1978. Cmnd 412. Her Majesty's Stationery Office, London.

Corby, B., Miller, M. \& Young, L. (1996) Parental participation in child protection work: rethinking the rhetoric. British fournal of Social Work, 26, 475-492.

De'Ath E. \& Pugh G. (eds) (1985-1986) Partnership Papers. National Children's Bureau, London.

Department for Children, Schools and Families (2008) The Children Act 1989 Guidance and Regulations Volume 1: Court Orders. The Stationery Office, London.

Department for Constitutional Affairs (2006a) Review of Childcare Proceedings in England and Wales. Department for Constitutional Affairs, London.

Department for Constitutional Affairs (2006b) Legal Aid - A Market-based Approach to Reform (Lord Carter's Review of Legal Aid Procurement). Department for Constitutional Affairs, London.

Department for Education and Skills (2004) Every Child Matters: The Next Steps. Her Majesty's Stationery Office, London.

Department for Education and Skills (2007) Every Parent Matters. Her Majesty's Stationery Office, London.

Department of Health (1989) The Care of Children: Principles and Practice in Regulations and Guidance. Her Majesty's Stationery Office, London.

Department of Health (1991) The Children Act 1989: Guidance and Regulations Volume 2, Family Support, Day Care and Educational Provision for Young People. Her Majesty's Stationery Office, London.

Department of Health (1995) Child Protection: Messages from Research. Her Majesty's Stationery Office, London.

Department of Health (2000) Framework for the Assessment of Children in Need and Their Families. Her Majesty's Stationery Office, London.
Department of Health and Social Security (1985a) Review of Child Care Law: Report to Ministers of an Interdepartmental Working Party. Her Majesty's Stationery Office, London.

Department of Health and Social Security (1985b) Place of Safety and Interim Care Orders: Review of Child Care Law. Her Majesty's Stationery Office, London.

Edwards, S. \& Halpern, A. (1992) Parental responsibility: an instrument of social policy. Family Law, 22, 113-118.

Farmer, E. \& Owen, M. (1995) Decision-Making, Intervention and Outcome in Child Protection Work. Her Majesty's Stationery Office, London.

Featherstone, B. (2009) Contemporary Fathering. Theory Policy and Practice. Policy Press, Bristol.

Forrester, D., McCambridge, J., Waissbein, C. \& Rollnick, S. (2008) How do child and family social workers talk to parents about child welfare concerns? Child Abuse Review, 17, 23-35.

Freeman, P. \& Hunt, J. (1998) Parental Perspectives on Care Proceedings. The Stationery Office, London.

Gallagher, F. \& Jasper, M. (2003) Health visitors' experiences of family group conferences in relation to child protection planning: a phenomenological study. Fournal of Nursing Management, 11, 377-386.

Gillen, S. (2009) Care proceedings and applications post-Baby P. Community Care Archive. Available at: http://www.community care.co.uk/Articles/2009/01/14/110406/how-the-public-lawoutline-is-affecting-care-cases-in-the-wake-of-baby.html (accessed 20 April 2009).

Gillies, V. (2005) Meeting parents needs: discourses of 'support' and 'inclusion' in family policy. Critical Social Policy, 25, 70-90.

Grover, C. (2008) Crime and Inequality. Willan, Devon.

Hall, C., Parton., N., Peckover, S. \& White, S. Child-centric ICTs and the fragmentation of child welfare practice. fournal of Social Policy, in press (available from lead author: c.j.hall@, hud.ac.uk).

Harlow, E. \& Shardlow, S. (2006) Safeguarding children: challenges to the effective operation of core groups. Child $\mathcal{E}$ Family Social Work, 11, 65-72.

Holland, S. \& Scourfield, J. (2004) Liberty and respect in child protection. British fournal of Social Work, 24, 17-32.

Hunt, J. (1998) A moving target - care proceedings a dynamic process. Child and Family Law Quarterly, 10, 281-289.

Hunt, J., Macleod, A. \& Thomas, C. (1999) The Last Resort: Child Protection, the Courts and the 1989 Children Act. The Stationery Office, London.

Judicial Review Team (2005) Thematic Review of the Protocol for fudicial Case Management in Public Law Children Act Cases. The Stationery Office, London.

Kaganas, F. (1995) Partnership under the Children Act 1989: an overview. In: Legislating for Harmony (eds F. Kaganas, M. King \& C. Piper), pp. 1-20. Jessica Kingsley, London.

Kaganas, F., King, M. \& Piper, C. (eds) (1995) Legislating for Harmony. Jessica Kingsley, London.

King, M. (1995) Partnership in politics and law: a new deal for parents? In: Legislating for Harmony, Partnership under the Children Act 1989 (eds F. Kaganas, M. King \& C. Piper), pp. 143-153. Jessica Kingsley, London. 
Lindley, B. (1994) Families in Court: Final Report. A Qualitative Study of the Experiences of the Court Process in Care and Supervision Proceedings under the Children Act. Family Rights Group, London.

Longstaff, D. (1998) Partnership: a social work perspective on preparing children and families for the initial child protection conference. MSW thesis, University of York, York.

Luckock, B. (2008) Adoption support and the negotiation of ambivalence in family policy and children's services. Fournal of Law and Society, 35, 3-27.

Marsh, P. \& Crow, G. (1998) Family Group Conferences in Child Welfare. Blackwell, Oxford.

Masson, J. (1995) Partnership with parents: doing something together under the Children Act 1989. In: Legislating for Harmony (eds F. Kaganas, M. King \& C. Piper), pp. 21-34. Jessica Kingsley, London.

Masson, J. (2008) Controlling costs and maintaining services the reform of legal aid fees for care proceedings. Child and Family Law Quarterly, 20, 425-448.

Masson, J., Pearce, J. \& Bader, K. (with Joyner, O., Marsden, J. \& Westlake, D.) (2008) Care Profiling Study. Ministry of Justice, London.

McKeigue, B. \& Beckett, C. (2008) Squeezing the toothpaste tube: will tackling court delay result in pre-court delay in its place? British fournal of SocialWork, doi: 10.1093/bjsw/bcn119.

Milham, S., Bullock, R., Hosie, K. \& Little, M. (1986) Lost in Care: The Problems of Maintaining Links between Children in Care and Their Families. Gower, Aldershot.

Ministry of Justice (2008) Public Law Outline. Ministry of Justice, London.

Muncie, J. (2006) Governing young people. Coherence and contradiction in contemporary youth justice. Critical Social Policy, 26, 770-793.

Nelken, D. (1987) The use of 'contracts' as a social work technique. In: Current Legal Problems (eds J. Jowell \& R. Rideout), pp. 217-232. Sweet \& Maxwell, London.

Parkinson, P. (2003) Child protection, permanency planning and children's rights to family life. International fournal of Law, Policy and the Family, 17, 1-18.

Petrie, S. \& Corby, B. (2002) Partnership with parents. In: The Child Protection Handbook (eds K. Wilson \& A. James), pp. 387-402. Balliere Tindall (Harcourt), London.

Piper, C. (2008) Investing in Children: Policy, Law and Practice in Context. Willan, Cullompton.

Price, D. \& Laybourne, A. (2008) The Work of the Family Bar: Report of the Week-at-a-glance Survey. Kings College, London.

Pugh, G. \& De'Ath, E. (1985) The Needs of Parents. Macmillan, London.
Pugh, G., Aplin, G., De'Ath, E. \& Moxon, M. (1987) Partnership in Action. Working with Parents in Pre-school Centre. National Children's Bureau, London.

Shaw, I., Bell, M., Sinclair, I., Sloper, P., Mitchell, W., Dyson, P. et al. (2009) An exemplary scheme? An evaluation of the Integrated Children's System. British Fournal of Social Work, Advance Access, published on 8 April 2009, doi: 10.1093/bjsw/ bcp040.

Thoburn, J., Lewis, A. \& Shemmings, D. (1995) Paternalism or Partnership? The Involvement of Family Members in Child Protection. Her Majesty's Stationery Office, London.

Welbourne, P. (2008) Safeguarding children on the edge of care: policy for keeping children safe after the Review of the Child Care Proceedings System, Care Matters and the Carter Review of Legal Aid. Child and Family Law Quarterly, CFLQ, $335,1-23$.

White, S. \& Broadhurst, K. (2009) Raging against the machine. Professional Social Work, January, pp. 8-10.

Woodhouse, S. (1995) Child protection and working in partnership with parents. In: Legislating for Harmony (ed. F. Kaganas), pp. 132-142. Jessica Kingsley, London.

\section{NOTE}

1 We use parent to denote parents/carers. In practice, the majority of parents involved with child protection agencies are lone mothers. Despite attempts to 'modernise' fatherhood, as Featherstone (2009) discusses, fathers remain marginal in terms of seeking care of their children in Public Law Children Act cases.

2 Local Authorities will also face a further disincentive to initiate care proceedings because of the new fee structure for this work. The new fee structure, detailed under s2(2) of the Family Proceedings Fees Order 2008 and s10(2) of the Magistrates Court Fees Order 2008, effective 1 May 2008, requires a local authority to pay up to $£ 4825$ instead of a previous $£ 150$ per case.

3 In situations where adoption is deemed a suitable option for a child (primarily in the case of young children where there are concerns or evidence of significant harm) children may be subject to a plan that has two pathways, one would be a reunification with his/her parents/family, the other to place the child for adoption - see B. Luckock (2008) for a further discussion.miscellaneoustext 